\title{
Compact Multiband Antenna with Asymmetric CPW Feed with Improved Performance
}

\author{
Radhika Shandilya \\ Thapar Institute of Engineering and Technology \\ Patiala, India
}

\author{
Rajesh Khanna \\ Thapar Institute of Engineering and Technology \\ Patiala, India
}

\begin{abstract}
A $50 \Omega$ asymmetric coplanar strip fed monopole antenna is being presented for multiband applications. The proposed antenna resonates around $2.4 \mathrm{GHz}, 4.78 \mathrm{GHz}$, and $5.5 \mathrm{GHz}$ and offers a very wide bandwidth of $1.77 \mathrm{GHz}(4.53 \mathrm{GHz}-$ $6.3 \mathrm{GHz}$ ) defined by $10 \mathrm{~dB}$ return loss covering four bands i.e. 4GHz C, IEEE $802.11 \mathrm{~b} / \mathrm{g}$, IEEE802.11a and HIPERLAN2. The multiband characteristic of the antenna is a result of various meandered strips' width excited in the radiating structure. The uniplanar design, simple feeding technique and compactness makes it easy for the integration of the antenna into the circuit boards. Details of the antenna design and simulation results are presented and discussed.
\end{abstract}

\section{General Terms}

Monopole antenna, Antenna theory.

\section{Keywords}

Asymmetric coplanar strip (ACS), multiband antennas, uniplanar monopole antenna.

\section{INTRODUCTION}

Wireless communication has evolved at astonishing rates during the last decade. Many techniques have been developed to meet the needs of multiband and multimedia handset antennas for third generation mobile systems. Some of these techniques involve planar patch inverted F (PIFA) antenna, printed dipole antenna and planar monopole antenna. Among these, the planar monopole antennas have received much more interest than others owing to their potential in providing desired features like multiband, wide bandwidth, and low profile [8]. However, such types of antennas mostly need a large size of ground plane, which is often printed on the different side of the substrate from the radiating plane, and thus a via-hole connection is always necessary for feeding the signal. This increases the manufacturing difficulty and cost. Coplanar waveguide feed is widely used as a uniplanar feeding technique and several antennas are made using this feeding mechanism. CPW fed antennas have various advantages like wide bandwidth, low profile, and light weight [6]. In this paper a compact multiband monopole antenna is presented. Emphasis is given to both design of the antenna feed and the radiating structure. Asymmetric coplanar strip (ACS) feeding is used in this design so that a simplified single layer feed structure is obtained. A meandered inverted $\mathrm{C}$ patch is chosen as the radiating structure to excite lower frequencies within a smaller area [9].

\section{PROPOSED ACS FED TOP LOADED MONOPOLE ANTENNA}

In this paper, inverted-C patch top loaded monopole antenna with the ACS feed is discussed and simulation studies have been carried out by varying the geometrical parameters of the antenna and their effect is studied on the performance of the antenna.

\subsection{Antenna Design}

Antenna design in Fig.1.shows the geometry and dimensions of the proposed antenna for multiband application. The antenna is excited by a CPW line of $50 \Omega$ and is printed on the FR4 substrate with a thickness of $1.5 \mathrm{~mm}$ and relative permittivity of 4.3 . The antenna comprises an inverted C patch top loaded monopole which is excited by an ACS feed. The $\mathrm{C}$ patch is used to bring down the resonant frequency, keeping the antenna dimensions within the desired specifications. The feeding arrangement comprises of a signal strip of width $\mathrm{S}$ and length $W_{g}$ separated from the ground plane of length $L_{g}$ and width $W_{g}$ by a gap $g$. (Fig.1). The radiating structure comprises of two vertical strips, two horizontal strips and a substrate $\mathrm{L} \times \mathrm{W}$. The lengths of the individual strips are selected to obtain resonances at the desired frequencies. The width of the strips are adjusted to obtain the required bandwidth. The optimum dimensions of the strip and the ground plane are obtained after an exhaustive simulation studies. The uniplanar antenna can be easily printed on the single side of a substrate. The Radiating slots form an array. As the dielectric constant increases, the resonant length of the patch decreases, which decreases the spacing between the two radiating slots.

The electric field from a single slot with a voltage $V_{0}$ across the slot is given as [1]:

$$
E_{\varnothing}=-\mathrm{j} 2 V_{0} \mathrm{~b} k_{0} \frac{e^{-j k_{0} r}}{4 \pi r} F(\theta, \varnothing)
$$

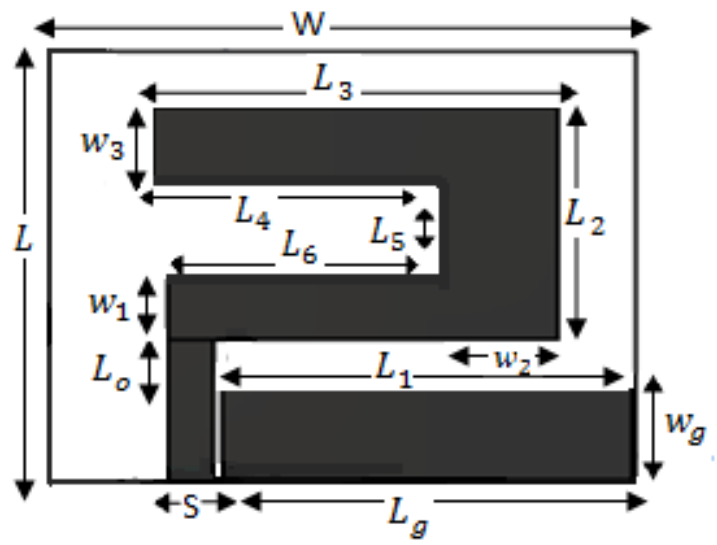

Figure 1 Geometry of the proposed multiband antenna

$L_{g}=26.8 \mathrm{~mm}, W_{g}=8 \mathrm{~mm}, \mathrm{~S}=3 \mathrm{~mm}, \mathrm{~g}=0.5 \mathrm{~mm}, \mathrm{~L}=$ $33.1 \mathrm{~mm}, W=33.4 \mathrm{~mm}, L_{5}=5.55 \mathrm{~mm}, L_{3}=26.5 \mathrm{~mm}, L_{2}=$ $18.1 \mathrm{~mm}, L_{4}=19 \mathrm{~mm}, L_{6}=17.8 \mathrm{~mm}, W_{3}=6.75 \mathrm{~mm}, W_{1}=$ $5.8 \mathrm{~mm}, L_{O}=2.7 \mathrm{~mm}, L_{1}=27.3 \mathrm{~mm}$. 


$$
\begin{gathered}
E_{\theta}=0 \\
\mathrm{~F}(\theta, \varnothing)=\frac{\sin \left(k_{0}\left(\frac{h}{2}\right) \sin \theta \cos \emptyset\right)}{k_{0}\left(\frac{h}{2}\right) \sin \theta \cos \emptyset} \cdot \frac{\sin \left(k_{0}\left(\frac{b}{2}\right) \cos \theta\right)}{k_{0}\left(\frac{b}{2}\right) \cos \theta} \sin \theta
\end{gathered}
$$

The E- plane radiation pattern for the slot is given by [1]:

$$
F_{E}(\varnothing)=\frac{\sin \left(k_{0}\left(\frac{h}{2}\right) \cos \emptyset\right)}{k_{0}\left(\frac{h}{2}\right) \cos \emptyset} \cdot \cos k_{0} b / 2 \cos \emptyset
$$

The H-plane pattern is independent of the slot spacing and is given by:

$$
\mathrm{F}(\theta)=\frac{\sin \left(k_{0} b \cos \theta\right)}{k_{0} b \cos \theta} \sin \theta
$$

The angle $\theta$ is measured from the $\mathrm{z}$ axis and $\varnothing$ is measured from the $\mathrm{x}$ axis.

The directivity of a single slot is calculated as:

$$
\mathrm{D}=\frac{4 b^{2} \pi^{2}}{I_{1 \lambda_{0}}{ }^{2}}
$$

$I_{1}=\int_{0}^{\pi} \sin ^{2}\left(k_{0} b \cos \theta\right) / 2 \tan \theta^{2} \sin \theta d \theta$

The directivity $D_{S}$ for a pair of radiating slots is given by:

$$
D_{s}=\frac{2 D}{1+g_{12}}
$$

Where,

$$
\frac{g_{12}=}{120 \pi^{2}}\left(\int_{0}^{\pi} \sin ^{2}\left(\frac{\pi b \cos \theta}{\lambda_{0}}\right) \tan \theta^{2} \sin \theta J_{0}\left(\frac{2 \pi a}{\lambda_{0}} \sin \theta\right) d \theta\right) / G
$$

$J_{0}(x)$ is the zeroth order Bessel function $\mathrm{x}$ [2].

$$
\mathrm{G}=\frac{1}{R_{r}}
$$

The radiation resistance $R_{r}$ is given by:

$$
\mathrm{R}_{\mathrm{r}}=\frac{120 \pi^{2}}{I_{1}}
$$

\subsection{Results and Discussions}

The measured return loss characteristics of the prototype antenna printed on FR4 substrate with a dielectric constant 4.3 and thickness $1.5 \mathrm{~mm}$ using CST STUDIO SUITE is shown in
Fig.2. The simulated curve obtained shows that antenna has three resonances at 2.39, 4.78 and $5.54 \mathrm{GHz}$. The first resonance forms a narrowband operating at $2.39 \mathrm{GHz}$. The second and third bands coalesce to give a very wide bandwidth of $1.77 \mathrm{GHz}$ (4.53 to 6.3). . The performance of the antenna is studied by varying the geometrical parameters of the antenna. The return loss measured at $2.39 \mathrm{GHz}$ is around $20 \mathrm{~dB}$.The second resonant frequency is at $4.78 \mathrm{GHz}$ and the third resonant frequency is at $5.54 \mathrm{GHz}$. The second and third resonant frequencies exhibits a good return loss of $35 \mathrm{~dB}$.Hence the proposed antenna has a good return loss characteristics.

The effect of different parameters on the performance of the antenna is discussed below.

\subsubsection{Effect of Varying Patch Width}

The width of the patch affects mainly the third resonant frequency and optimum performance is obtained when patch width is $18.1 \mathrm{~mm}$

\subsubsection{Effect of varying slot length}

The length of the slot affects mainly the second and third resonant frequencies. The second resonant frequency is at $4.78 \mathrm{GHz}$ and the third resonant frequency is at $5.54 \mathrm{GHz}$.

\subsubsection{The Electric field pattern}

The Electric field pattern of the antenna for the three resonant frequencies is shown in Fig.5. As the operating band gets higher, the efficiency increases and gain decreases which are desirable radiation characteristics of an antenna.

\subsubsection{Surface current distribution}

Surface current distribution of the antenna for the three resonant frequencies is shown in Fig.6. The surface current is distributed along the inverted $\mathrm{C}$ patch.

\section{S-Parameter Magnitude in dB}

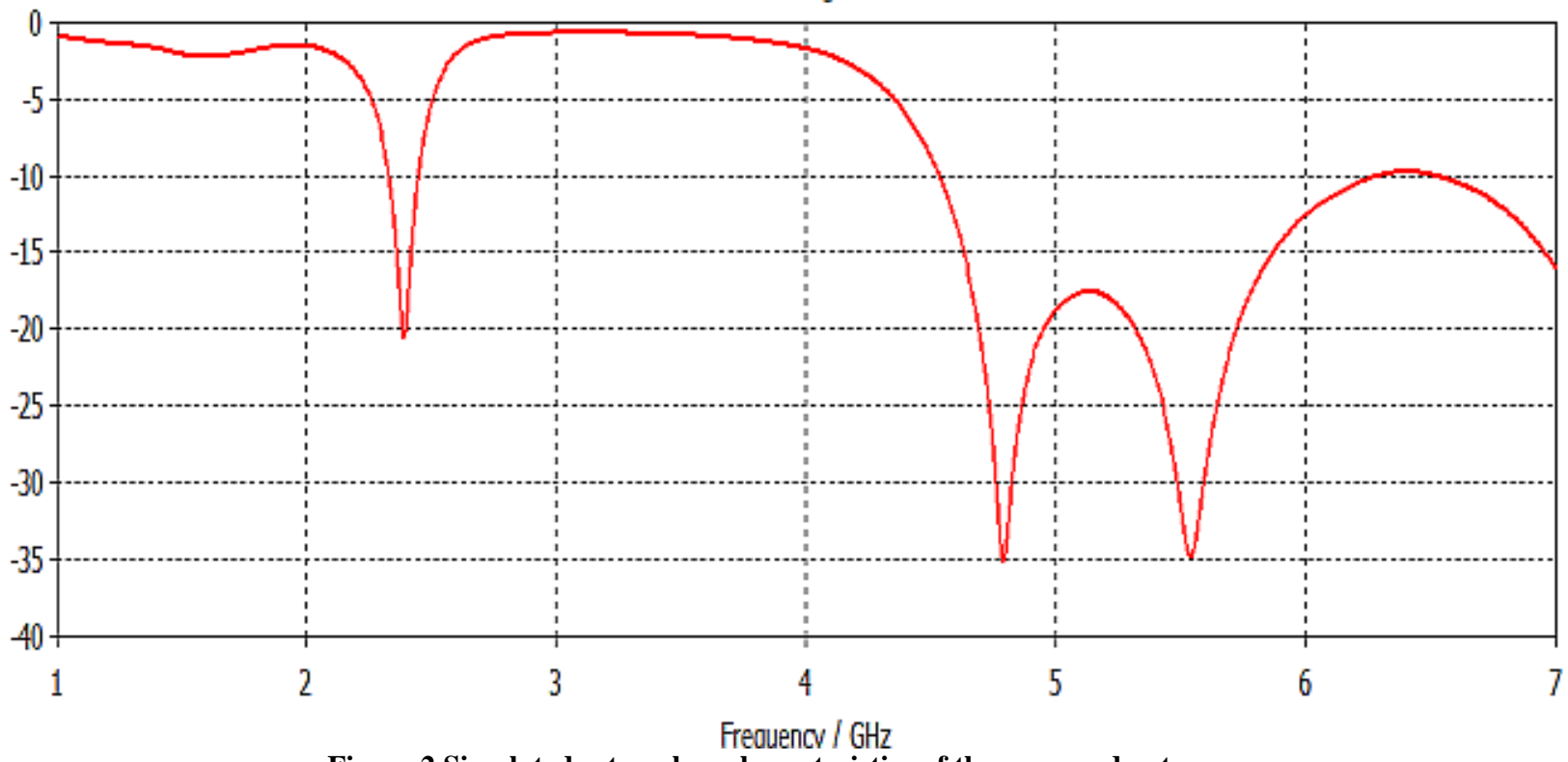

Figure 2 Simulated return loss characteristics of the proposed antenna 


\section{$|52,2|$ in $\mathrm{dB}$}

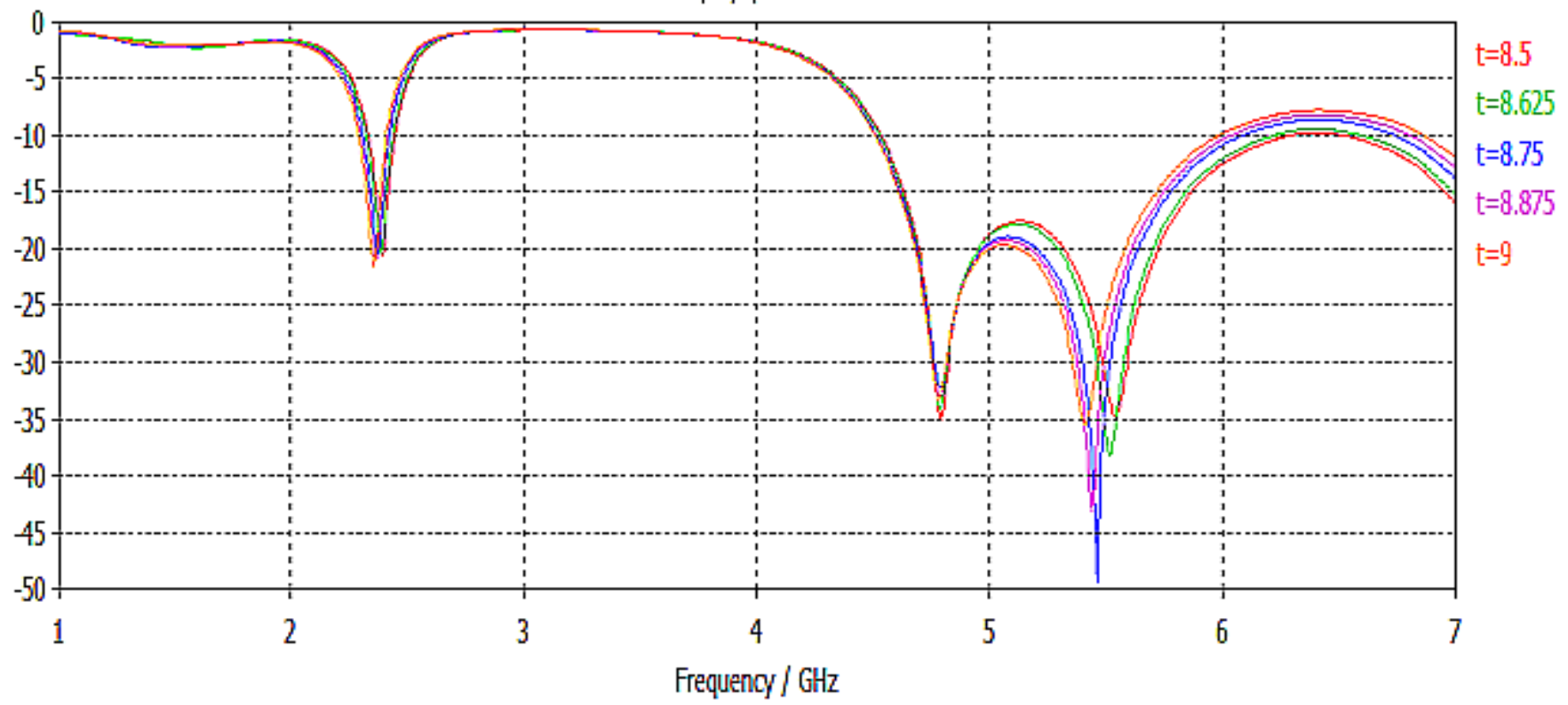

Figure 3 Effect of varying patch width

$\left|52_{\mathrm{r}}\right| \mathrm{in}_{\mathrm{d}} \mathrm{dB}$

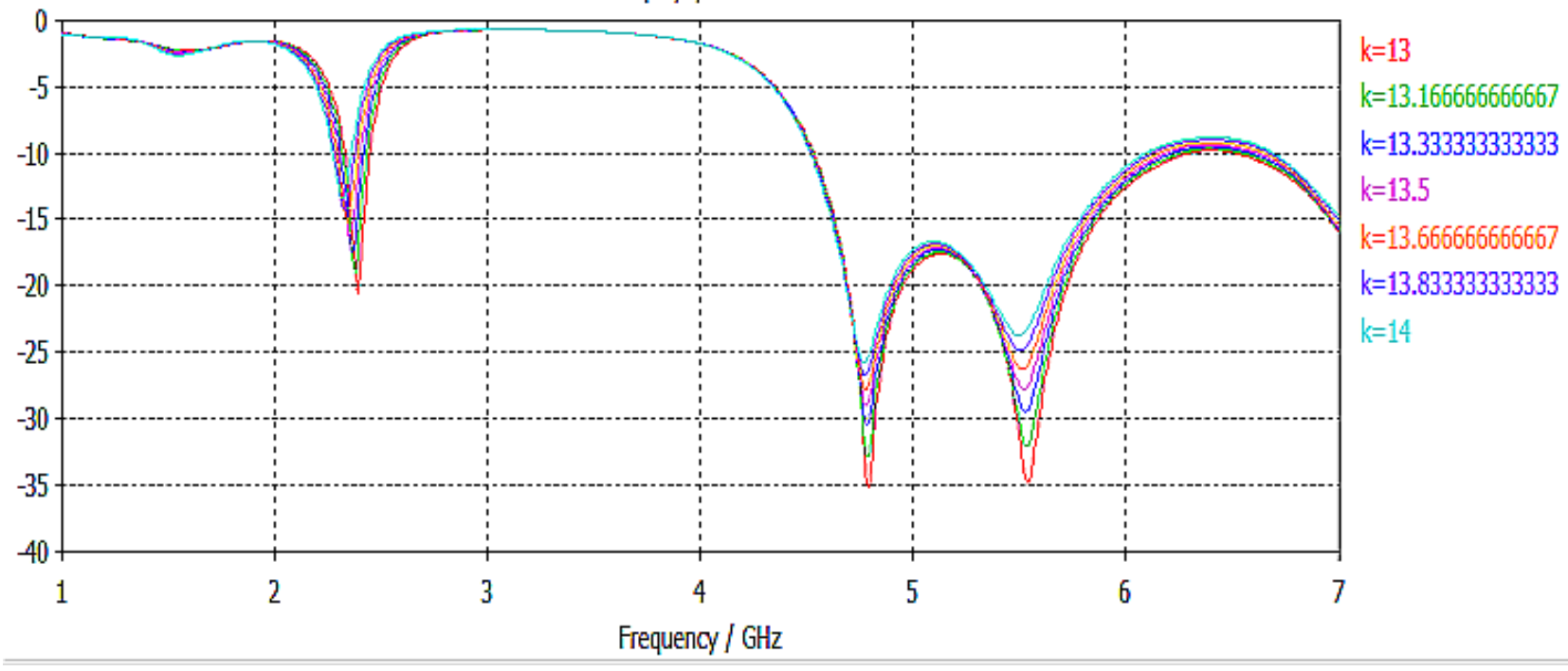

Figure 4 Effect of varying slot length

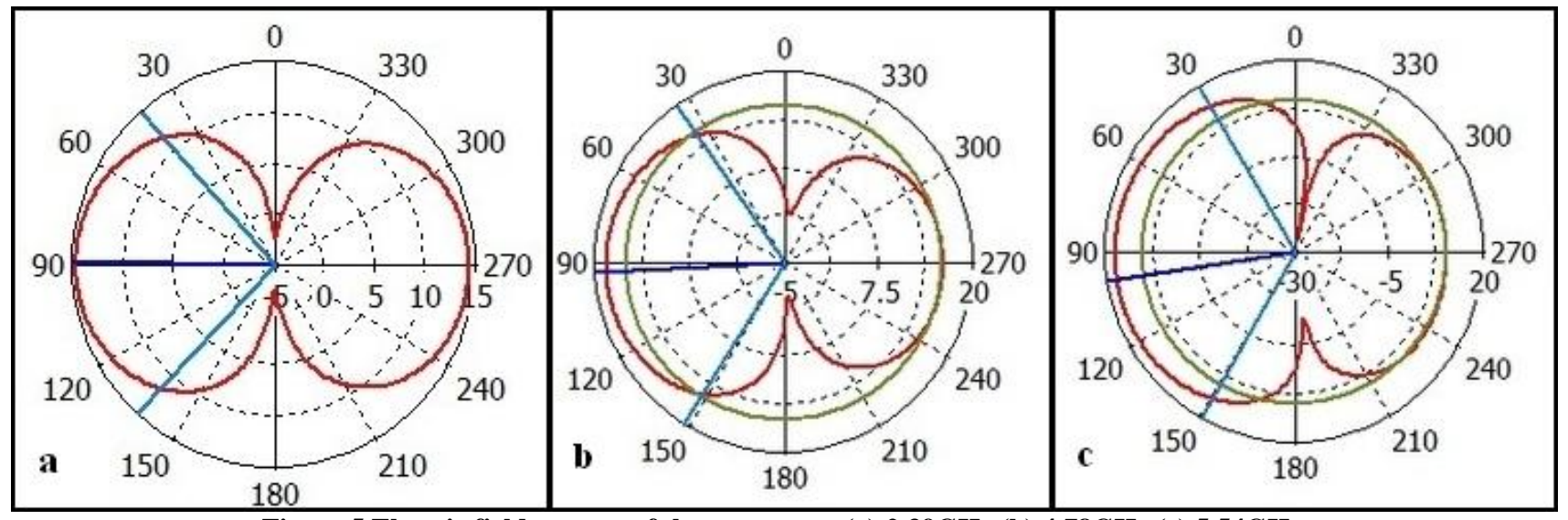

Figure 5 Electric field pattern of the antenna at (a) $2.39 \mathrm{GHz}$ (b) $4.78 \mathrm{GHz}$ (c) $5.54 \mathrm{GHz}$ 


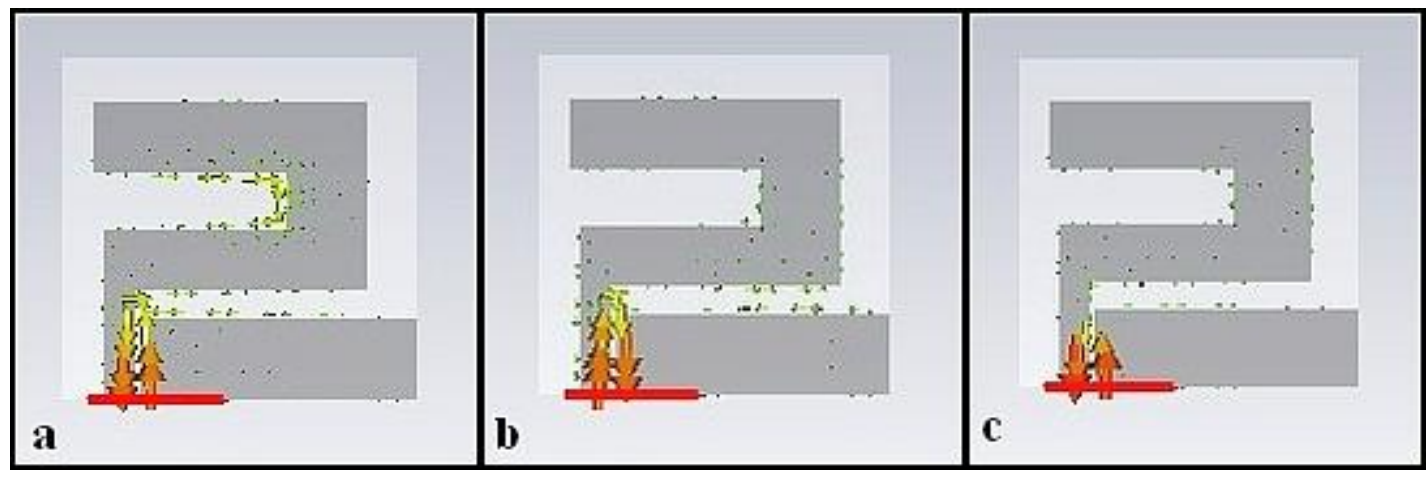

Figure 6 Surface current distribution at (a) $2.39 \mathrm{GHz}$ (b) $4.78 \mathrm{GHz}$ (c) $5.54 \mathrm{GHz}$

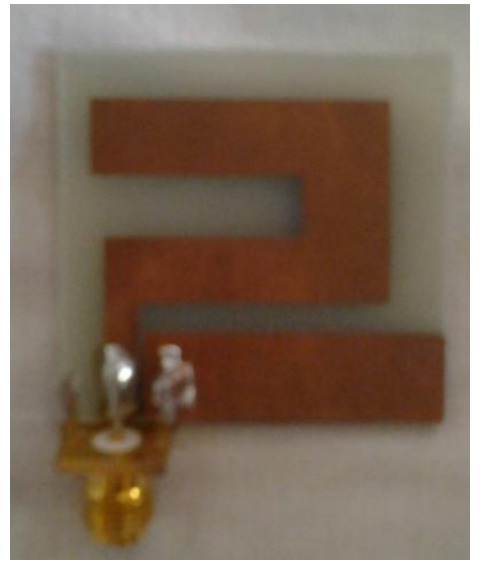

Figure 7 Proposed multiband antenna

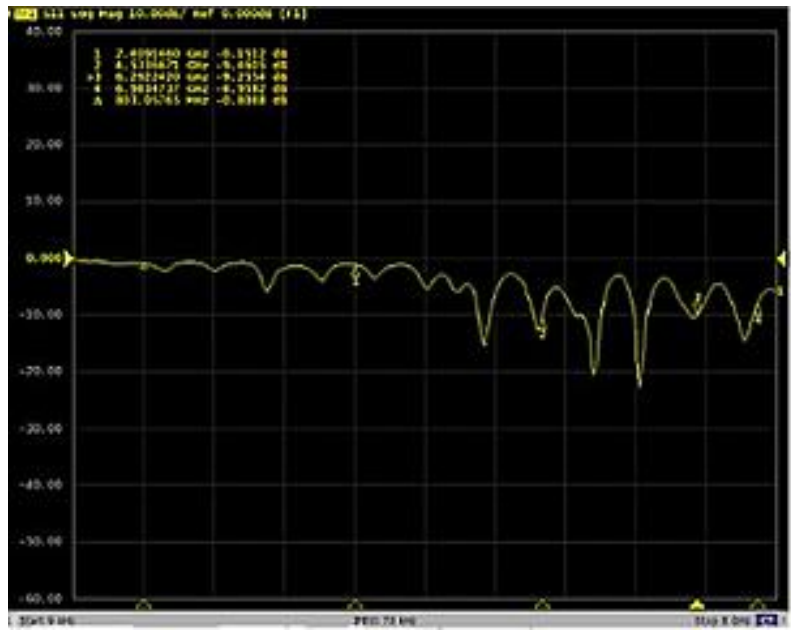

Figure 8 Practical return loss characteristic curve of the proposed multiband antenna

The practical and the simulated results show that a dual band is formed in the desired frequency range of $4.53 \mathrm{GHz}$ to $6.3 \mathrm{GHz}$. The two resonant peaks are at around $-20 \mathrm{~dB}$ and $35 \mathrm{~dB}$.

\section{CONCLUSION}

A compact multiband antenna covering four bands $4 \mathrm{GHz} \mathrm{C}$ band IEEE802.11b/g, IEEE802.11a, HIPERLAN2 is discussed. In this paper compactness is achieved by using an ACS feed and a meandered radiating structure. The antenna presents a very wide bandwidth of $1.77 \mathrm{GHz}$. The design can be used for constructing compact antennas for wireless gadgets.

\section{LIST OF ABBREVIATIONS}

CPW: Co-planar waveguide

ACS: Asymmetric coplanar strip

PIFA: Planar Inverted-F (type) Antenna 


\section{ACKNOWLEDGEMENT}

The authors thank Thapar Institute of Engineering and Technology, Patiala for allowing us to carry out the measurements for the study of the proposed antenna.

\section{REFERENCES}

[1] R. Garg, P. Bhartia, and I. Bahl, Microstrip Antenna Design Hand book, 1st ed. Boston, MA: Artech House, 2001, pp. 794-795.

[2] K.D Prasad, "Antenna \& Wave Propagation", 3rd Edition 2010

[3] Balanis, C.A., "Antenna Theory Analysis and Design" 3rd Edition, New jersey: John Wiley

[4] Yazi Cao, Member, IEEE, Bo Yuan, and Gaofeng Wang, Senior Member, IEEE"A Compact Multiband OpenEnded Slot Antenna for Mobile Handsets" IEEE antennas and wireless propagation letters, Vol. 10, pp. 353-357,Aug. 2011

[5] W.-C. Liu1, M. Ghavami2, W.-C. Chung1 "Triplefrequency meandered monopole antenna with shorted parasitic strips for wireless application" IET Microw. Antennas Propag. 2009, Vol. 3, Iss. 7, pp. 1110-1117.
[6] W. C. Liu and W. R. Chen, "CPW-fed compact meandered patch antenna for dual-band operation," IEEE Electron. Lett. Vol. 40, no. 18, pp. 1094-1095, Sep. 2004

[7] Kin-Lu Wong, Senior Member, IEEE, Gwo-Yun Lee, and Tzung-Wern Chiou" A Low-Profile Planar Monopole Antenna for Multiband Operation of Mobile Handsets" IEEE Transactions Antennas and Propagation, Vol. 51, no.1, pp. 121-125, Jan. 2003

[8] Jui-Han Lu, Senior Member, IEEE, and Wen-Chieh Chou "Planar Dual U-Shaped Monopole Antenna with Multiband Operation for IEEE 802.16e" IEEE Antennas and Wireless Propagation Lett., Vol. 9, PP. 1006-1009.

[9] Deepu.V, Rohith K. Raj, Manoj Joseph, Suma M.N, and P. Mohanan, "Compact asymmetric coplanar strip fed monopole antenna for multiband applications," IEEE Trans. on Antennas and Propog.,vol.55,no.8,pp23512357,Aug. 2007

[10] Wen-Chung Liu, Senior Member, IEEE, Chao-Ming Wu, and Yang Dai "Design of Triple-Frequency MicrostripFed.

[11] Monopole Antenna Using Defected Ground Structure" IEEE Transactions on Antennas and Propagation, Vol 59 , no. 7, July 2011. 